\title{
Demographic trend and clinical features of brucellosis in patients with history of lower back pain - A study in tertiary care hospital
}

\author{
Mohite R.S. ${ }^{1}$, Inamdar D.P. ${ }^{2}$, Kulkarni V.A. ${ }^{3}$, Joshi P. ${ }^{4}$, Kulkarni R.D. ${ }^{5}$ \\ ${ }^{1}$ Dr.Ravindra S Mohite, Associate Professor, Department of Microbiology, Bharati Vidyapeeth (Deemed to be university) \\ Medical College and Hospital, Wanlesswadi, Sangli, Maharashtra, India, ${ }^{2}$ Dr.Dhanashree P Inamdar, Assistant Professor, \\ Department of Microbiology, Mamata Medical College and Hospital, Khammam, India, ${ }^{3}$ Dr. V.A. Kulkarni, Professor \\ and Head of Department, Department of Microbiology, Government Medical College and Hospital, Miraj, Maharashtra, \\ India, ${ }^{4}$ Dr. Pankaj Joshi, Associate Professor, Department of Microbiology, Government Medical College and Hospital, \\ Miraj, Maharashtra, ${ }^{5}$ Dr R.D. Kulkarni, Professor and HOD, Department of Microbiology, SDM Medical College and \\ Hospital, Dharwad, Karnataka, India.
}

Corresponding Author: Dr. Dhanashree P Inamdar, Microbiology, Assistant Professor, Mamata Medical College and Hospital, Khammam, India. Email: dhanashreeltmmc@gmail.com

\begin{abstract}
Introduction: Even though Lower Backpain (LBP) is the common symptom presenting to orthopedic OPD, not all the patients get relief from back pain. Due to complexity of the problem and heterogeneity of its nature many patients suffer from chronic lower back pain for long period. Infective agents do play a significant role in LBP and one of the differential diagnosis is Brucellosis. The present study is intended to find epidemiological correlation between brucellosis and LBP patients with pertinent serological tests and aid in decreasing morbidity associated with back pain. Materials and methods: Study involved evaluation of seventy adult patients $(n=70)$ with history of low back pain attending orthopedic OPD. A detailed history of fever, work atmosphere, occupation in animal husbandry and ingestion of raw milk were collected and followed by radiological investigation (X-ray lower back). After physical examination serum samples were collected from these patients. First year MBBS students $(n=30)$ without history of LBP were taken as controls. Results: Out of these 70 patients, seropositivity was seen in 10 patients by rapid slide agglutination test as screening procedure followed by tube agglutination test (SAT) as confirmatory test. Patients affected were men of 31 to 40 years age group. Incidence of brucellosis in our patients was $14.1 \%$. Most of them were farmers by occupation. Of these 6 gave history of ingestion of raw milk. 6 patients had history of occupational exposure to animals and fever was seen in 5 cases. Radiological findings were positive in 4 patients. Conclusion: Diagnosing Brucellosis in patients with chronic backache is a challenge due to heterogeneity of condition. High clinical suspicion in patients with rural back ground, relevant serological tests with radiological evidence help in clinching the diagnosis of brucellosis in patients with chronic lower backpain.
\end{abstract}

Keywords: Brucellosis, Low Back pain (LBP), SAT (standard agglutination test).

\section{Introduction}

Lower Backpain (LBP) is one of the most common complaint in patients attending outpatient clinic in orthopedic department. Studies indicate the annual worldwide LBP incidence in adults to be $15 \%$ [1] and the point prevalence to be $30 \%$ [2]. There are number of etiological factors in LBP which vary from trivial trauma to malignancy affecting the spine. There is increasing trend of back pain in developing countries and infective agents do play a significant role in LBP.

Manuscript received: $6^{\text {th }}$ January 2018

Reviewed: $16^{\text {th }}$ January 2018

Author Corrected: $25^{\text {th }}$ January 2018

Accepted for Publication: $31^{\text {st }}$ January 2018
Apart from Tuberculosis [3] and Propionibacterium acnes [4] commonly affecting spine, brucellosis could be one of the differential diagnosis. Being a zoonotic disease, long-term complication of brucellosis is musculoskeletal pain in the form of LBP [ 5,6,7]. In our Indian patients with rural back ground and occupational exposure to animals, diagnosis can be missed easily.

Diagnosis of brucellosis can be suspected in patients with relevant history of contact with animals along with radiological evidence. This will aid in serological diagnosis of case of brucellosis [8] where treatment 


\section{Original Research Article}

with antibiotics will significantly alter course of LBP and reduce morbidity associated with back ache. Thus, this present study was undertaken to see if brucellosis existed as a cause of lower back pain in Miraj and to identify the clinical setting in patients of backache where brucella serology is indicated. Confirmation of diagnosis was done by proper serological methods and culture which could aid measures for appropriate treatment in patients suffering from LBP.

\section{Material and Methods}

A prospective study was conducted at the Government Medical College, Miraj, Maharashtra after obtaining Institute Ethical Committee clearance.

Inclusion criteria- Study cohort involved seventy (70) consecutive adult patients with chronic backache attending the orthopedic out patient. Thirty (30) medical students of $1^{\text {st }}$ year MBBS with no history of fever or backache or animal contact were taken as control group.

Exclusion Criteria: Extremes of age group (less than $10 y$ rs to more than 80 years) were excluded from the study.

Sample collection: A detailed history of back ache was taken followed by physical examination. In history special emphasis was placed on rural/urban back ground, residing in endemic zone, history of fever, occupational exposure to animal, dietary exposure and work atmosphere was taken. Relevant radiological investigations like X-ray Dorso-lumbar spine were done. Patients were then subjected to serological tests which constituted screening test by Rapid Slide Agglutination for anti-Brucella antibodies.

The antigen used was Rose Bengal Plate Test (RBPT) antigen (Indian Veterinary Research Institute, Izatnagar) with sensitivity of $99 \%$ and a specificity of $97.6 \%$. But as sensitivity of RBPT is less in chronic LBP patients [9], confirmation was done by Standard tube agglutination (SAT) test [10] where antigen used was a suspension of a pure smooth culture of Brucella abortus strain 99 in phenol saline with sensitivity of $70 \%$ and specificity of $70 \%$. In chronic disease SAT may be negative or positive in low titers [11].

Another phenomenon observed in brucellosis is "blocking antibody" character of antibrucellar antibodies which is usually $\operatorname{IgG}$ or $\operatorname{IgA}$ variety. Though high titers usually indicate infection, low titer or negative reaction in SAT do not exclude the possibility of infection. This emphasizes the need to use more than one serological test for diagnosis [12].

Statistical analysis: All the data collected was entered in Microsoft excel sheet and relevant statistical tests like Fishers Exact two tailed Chi square test were done using SPSS software version 19. A p value less than 0.05 was taken as statistically significant.

\section{Results}

Demographic distribution of patients is shown in Table No 1. Men were affected more commonly, and most were in their third decade of life. Most of them were farmers by occupation. Among patients complaining of chronic low back pain 10 were tested positive for brucellosis by screening and confirmatory tests. Out of 10 patients who tested positive for brucellosis 8 were men and 2 were women.

History of occupational exposure to animals was seen in 6 patients among whom 5 were men and 1 was women and all belonged to rural background. History of exposure to animals was not seen in rest 4 patients. History of fever was seen only in 5 patients out of 10 Brucella patients. History of raw milk consumption was seen in 6 out of 10 patients with majority being men $(n=5)$. Radiological finding suggestive of brucellosis like disc space reduction (Fig 1), Bridging osteophyte suggestive of spondylitis (Fig 2) and osteolytic lesions with sclerosis were seen in 4 patients.

Of 70 patients complaining of backache $10(14.28 \%)$ patients were positive for Brucella by rapid slide agglutination tests. Subsequent determination of titer, all 10/10 sera samples showed antibodies in diagnostic titers (1:320) by Standard agglutination tests (SAT).

Blood culture however was negative for growth of Brucella spp. None of the healthy controls tested positive for presence of Brucella antibodies. Treatment with triple antibiotics, Doxycycline and rifampin with gentamicin for initial 2-3 weeks, followed by 6 weeks of rifampin and doxycycline was given.

The patients were followed for a period of 6 months and were asymptomatic at the end of 6 months. Among the controls none of the students tested positive for brucellosis. 
Original Research Article

Table No.-1: Demographic data of patients with Seropositivity $(n=10)$.

\begin{tabular}{|c|c|}
\hline Sex & Distribution \\
\hline Males & $\mathbf{8}$ \\
\hline Females & $\mathbf{2}$ \\
\hline Age Group & $\mathbf{3}$ \\
\hline $21-30$ & $\mathbf{5}$ \\
\hline $31-40$ & $\mathbf{2}$ \\
\hline $41-50$ & \\
\hline Occupation & $\mathbf{6}$ \\
\hline Farmer & $\mathbf{1}$ \\
\hline Dairy worker & $\mathbf{2}$ \\
\hline Others & $\mathbf{1}$ \\
\hline At home & $\mathbf{6}$ \\
\hline Residence & $\mathbf{4}$ \\
\hline Rural & \\
\hline Urban & \\
\hline & \\
\hline
\end{tabular}

Table No-2: Distribution of patients with clinical and radiological findings

\begin{tabular}{|c|c|c|}
\hline Total seropositive $(\mathbf{n}=\mathbf{1 0})$ & Males & Females \\
\hline Fever $(\mathrm{n}=5)$ & 3 & 2 \\
\hline H/O raw milk ingestion $(\mathrm{n}=6)$ & 5 & 1 \\
\hline H/O animal contact $(\mathrm{n}=6)$ & 5 & 1 \\
\hline Radiological findings $(\mathrm{n}=4)$ & 3 & 1 \\
\hline
\end{tabular}

\section{Discussion}

Brucellosis is a zoonotic disease caused by Brucella spp. Although Brucella is an intracellular pathogen causing systemic infection, which ranges from asymptomatic to severe manifestations its primary manifestation is fever, sweating, malaise, anorexia, headache, pain in muscles, joint, and/or back, fatigue. It can also affect bones and joints causing arthritis, bursitis, tenosynovitis, sacroiliitis, spondylitis and osteomyelitis which is regarded as the one of the common complication of brucellosis. As Spondylitis is the most common osteoarticular complication due to brucellosis [13] chronic backache is usually complained by these patients and such patients tend to cluster more in orthopedic OPDs.

In the present study men were most commonly affected out of 10 seropositive cases which could be attributed to outdoor activity with occupational exposure during agricultural activity. Most were young men between 31-40 years. Our study is comparable to study done by Bin Jia et al [14] in-Xinjiangprovince, an agriculture dominated area in western china.

Occupation plays a vital role in brucellosis. As brucellosis is a zoonotic disease more often seen occupational groups like dairy workers, butchers, abattoir workers and farmers. Veterinarian occupational history needs to be kept in mind while dealing with patients complaining of backache. In present study history of contact with domestic animals could be elicited in 6 cases and history of ingestion of raw milk was seen also in 6 cases. In three cases there was history of both animal contact and ingestion of raw milk or cheese. Similar findings were noted by Mahakur and Panda et al [15]. Various studies done have shown that animal contact can be traced in many cases of brucellosis. Virtually all infections derive directly or indirectly from animal exposure [16]. Most cases of infection caused by Br. abortus, Br. melitensis, Br.ovis, and Br.canis arise from occupational or domestic contact with infected animals or with an environment contaminated by their discharges. Infected animals that have recently aborted or given birth present the greatest hazard [07]. It is also suggested that ingestion of unpasteurized goat milk leads to brucellosis according to studies by Zaks N.et al[17], Gokhale Y.A.et al [18].

In present study, out of 10 serologically positive cases, 5 cases showed associated history of fever while remaining cases were a febrile. It is consistent with study done by Nagalotimath et al [19]. One should note that majority of chronic cases 


\section{Original Research Article}

of brucellosis are devoid of fever. Hence, fever need not to be taken as a diagnostic feature of brucellosis. But as brucellosis is considered as one of the causes of pyrexia of unknown origin fever history should be interpreted cautiously.

Radiological findings to differentiate tubercular spondylitis from Brucella spondylitis is important as the former is more common in our country. Involvement of multiple vertebral bodies with involvement of disc space suggests tubercular spondylitis [20]. Characteristic findings of brucellar spondylitis are predilection for the lower lumbar spine $(68 \%$ of lesions), bone destruction limited to the end plates, disk collapse, and granulation tissue or localized soft-tissue edema [21]. The radiological findings seen in our study suggests that brucellosis has effect on musculoskeletal system and our findings were similar to studies done by OzgulAet al [22], Sadat-Al M. et al [23] but differs from study of SankaranKuttyet al [24] who found that clinical, radiological and histological features are not specific for diagnosing brucellosis.

One author Rajapaskeet al [25] found bone scanning was more sensitive than radiographs particularly in detecting acute sacroiliitis. Kheteeb et al [26], Malik G. M. et al [27] found that sacroiliitis being the most common presentation in brucellosis patients which is regarded as the common osteoarticular complication of brucellosis.

Blood Culture is regarded as gold standard in definite diagnosis of brucellosis but due to inefficiency, danger involved during isolation, serology is the cost-effective procedure [28]. Serological diagnosis helps in decreasing the morbidity among chronic spondylarthritis patients. Serology has a vital role in brucellosis as new screening tests by rapid slide agglutination methods are available. Serology is considered as confirmatory evidence for brucellosis keeping the background and contact history of patient [29]. In the present study 10 cases were positive for Brucella agglutinins in their sera and also present in diagnostic titers. In our study the incidence of brucellosis in Backache has been found to be $14.2 \%$. High Incidence was probably due to small sample size of our study. But correlates with the findings of the studies done by Gokhale and Bichile et al (8.3\%) [18] and Mousa and Muhtaseb et al (6\%) [30].

Though there are reports of brucellosis in backache patients from various parts of World, it is just the tip of the iceberg, as many cases remain undiagnosed. The failure to diagnose brucellosis is due to the failure to suspect it. The only way to diagnose it is to suspect it and then to have a serological test on the patient's serum and if it is positive to proceed with blood culture [28].

We acknowledge the limitations of our study. Our sample size was small and study in larger population needs to be done to establish the role. The clinicians miss the diagnosis of brucellosis due to lack of awareness and high clinical suspicion. A history of occupational or environmental exposure to possible sources of infection should always be sought. The awareness of the disease in the people involved in veterinary profession is also of prime importance.

This would help to take necessary preventive measures. It is suggested that the individuals engaged in an occupation which brings them in contact with Brucella infected animals and Brucella cultures should be screened periodically for Brucella agglutinin [31].

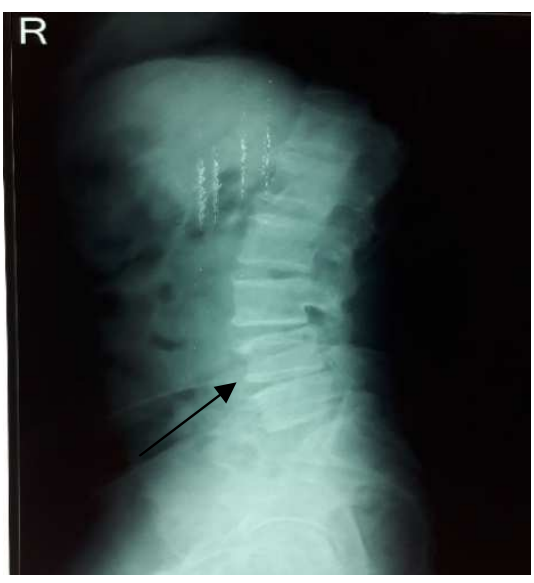

Fig.1: $X$ ray Dorsolumbar spine lateral view showing reduction in disc space between $\mathrm{L} 4$ and $\mathrm{L} 5$.

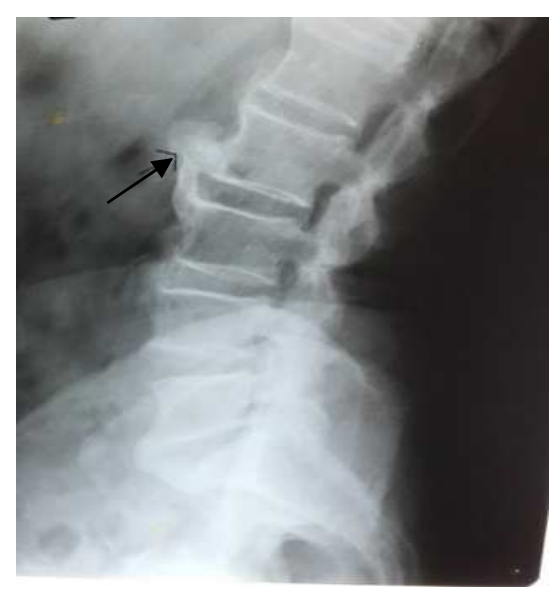

Fig-2: $X$ ray Dorsolumbar spine lateral view showing Bridging osteophyte between $L 2$ and $L 3$ (indicated by arrow) 


\section{Original Research Article}

\section{Conclusion}

To conclude the role of infective etiology should always be kept in mind in patients with chronic lower back pain. High clinical suspicion in patients working in animal husbandry and those come in contact with livestock like farmers should undergo a detailed testing. With brucellosis in mind relevant serological tests will help in establishing diagnosis due to their ease and cost effectiveness as there is difficulty in culturing this organism due to its fastidious nature and need for BSL (Biosafety Level)-3 precautions which is not available in every laboratory. Hence long-term analgesic treatment could be avoided and evidence-based treatment in the form of antibiotics should be started to these patients to relieve chronic low back pain.

Funding: Nil, Conflict of interest: None initiated, Permission from IRB: Yes

\section{References}

1. Andersson GB. Epidemiological features of chronic low-back pain. Lancet. 1999 Aug 14;354(9178):581-5.

2. Papageorgiou AC, Croft PR, Ferry S, Jayson MI, Silman AJ. Estimating the prevalence of low back pain in the general population. Evidence from the South Manchester Back Pain Survey. Spine (Phila Pa 1976). 1995 Sep 1;20(17):1889-94.

3. Garg RK, Somvanshi DS. Spinal tuberculosis: a review. J Spinal Cord Med. 2011;34(5):440-54. doi: 10. 1179/2045772311Y.0000000023.

4. Urquhart DM, Zheng Y, Cheng AC, Rosenfeld JV, Chan P, Liew S, Hussain SM, Cicuttini FM. Could low grade bacterial infection contribute to low back pain? A systematic review. BMC Med. 2015 Jan 22;13:13. doi: 10. 1186/s12916-015-0267-x.

5. Kil-Byung Lim. Back Pain Secondary to Brucella Spondylitis in the Lumbar Region. Ann Rehabil Med. 2012 Apr; 36(2): 282-286.

6. Taif S, Alrawi A. Spinal brucellosis: a forgotten cause of chronic back pain. BMJ Case Rep. 2014 Jul 2;2014. pii: bcr2014205816. doi: 10.1136/bcr-2014205816.

7. Tsimichodimos et al. Severe Low Back Pain Due to Brucella Spondylitis: A Case of Diagnostic and Therapeutic Challenge. Infect Dis ClinPract.Nov 2002; 11: 8437-440.
8. Gokhle YA, Bichile LS, Gogate A, Tillu AV, Zamre. Brucella spondylitis: an important treatable cause of low backache. J Assoc Physicians India. 1999 Apr; 47 (4): 384-8.

9. Ruiz-Mesa JD, Sánchez-Gonzalez J, Reguera JM, Martín L, Lopez-Palmero S, Colmenero JD. Rose Bengal test: diagnostic yield and use for the rapid diagnosis of human brucellosis in emergency departments in endemic areas. ClinMicrobiol Infect. 2005 Mar;11(3):221-5.

10. Young EJ. Serologic diagnosis of human brucellosis: analysis of 214 cases by agglutination tests and review of the literature. Rev Infect Dis. 1991 MayJun; 13 (3):359-72.

11. Kothari G. C. Brucellosis - a review.J J Group Hosp Grant Med Coll. 1956; 1(2): 140-157.

12. Sonnenwirth A. C. and Jarrett L. Gradwohl's Clinical Laboratory Methods and Diagnosis, Volume 2, 8th Edition.St.Louis:C.V.MosbyCo.,1980; 2305 - 2307.

13. Javier Solera et al Brucellar Spondylitis: Review of 35 Cases and Literature Survey.CID.1999; 29:1440-9.

14. Jia B, Zhang F, Lu Y, Zhang W, Li J, Zhang Y, et al. The clinical features of 590 patients with brucellosis in Xinjiang, China with the emphasis on the treatment of complications. 2017.PLoS Negl Trop Dis 11(5): e0005577. https: //doi. org/10.1371 /journal. pntd. 000 5577.

15. Mahakur AC, Panda GK. Incidence of brucellosis in and around Burla. Indian J Med Sci. 1972 Dec;26 (12):826-30.

16. Young E. Mandell, Douglus. Bennett's Principles and Practice of Infectious Diseases.4th ed. Vol.2. Newyork: Churchill - Livingstone;1995. 2053 -2060.

17. Zaks N, Sukenik S, Alkan M, Flusser D, Neumann L, Buskila D. Musculoskeletal manifestations of brucellosis: a study of 90 cases in Israel. Semin Arthritis Rheum. 1995 Oct;25(2):97-102.

18. Gokhle YA, Bichile LS, Gogate A, Tillu AV, Zamre. Brucella spondylitis: an important treatable cause of low backache. J Assoc Physicians India. 1999 Apr; 47 (4):384-8. 


\section{Original Research Article}

19. Nagalotimath S.J. Bones and Joints in Brucellosis. In: Kulkarni G.S. editor. Text book of Orthopedics and Trauma. 1st edn. Vol.1 Jaypee; 1999; 212-216.

20. Al-Nakshabandi NA. The spectrum of imaging findings of brucellosis: a pictorial essay. Can AssocRadiol J. 2012 Feb;63(1):5-11. doi: 10.1016/j. carj. 2010.09.011. Epub 2010 Nov 12.

21. Sharif HS, Aideyan OA, Clark DC, Madkour MM, Aabed MY, Mattsson TA, al-Deeb SM, Moutaery KR. Brucellar and tuberculous spondylitis: comparative imaging features. Radiology. 1989 May;171(2):419-25.

22. Ozgül A, Yazicioğlu K, Gündüz S, Kalyon TA, Arpacioğlu O. Acute brucella sacroiliitis: clinical features. ClinRheumatol. 1998;17(6):521-3.

23. Sadat-Ali M, al-Mousa MS, al-Salem AH. Brucellosis as a cause of backache. Trop Geogr Med. 1991 Jan-Apr;43(1-2):148-51.

24. Sankaran-Kutty M,MarwahS,KuttyMK.The skeletal manifestations of brucellosis.IntOrthop.1991;15(1):17-9

25. Rajapakse CN, Al-Aska AK, Al-Orainey I, Halim K, Arabi K. Spinal brucellosis. Br J Rheumatol. 1987 Feb; 26(1):28-31.
26. Khateeb MI, Araj GF, Majeed SA, Lulu AR. Brucella arthritis: a study of 96 cases in Kuwait. Ann Rheum Dis. 1990 Dec;49(12):994-8.

27. Malik GM. A clinical study of brucellosis in adults in the Asir region of southern Saudi Arabia. Am J Trop Med Hyg. 1997 Apr;56(4):375-7.

28. HCDCP.org[Internet]. Human brucellosis: diagnosis and treatment.[updated on June8, 2012] Available from; http://www2.keelpno.gr/blog/?p=2023\&lang=en.

29. CDC. gov.in [Internet]. Brucellosis Reference Guide: Exposures, Testing, And Prevention[ Updated on February 2017]. Available from;https:// www.cdc. gov/brucellosis/pdf/brucellosis-reference-guide.pdf

30. Mousa A.R et al.The nature of human brucellosis in Kuwait: study of 379 cases. Rev Infect Dis. 1988 JanFeb; 10(1):211-7.

31. Mathur TN. Brucella strains isolated from cows, buffaloes, goats, sheep and human beings at karnal: their significance with regard to the epidemiology of brucellosis. Indian J Med Res. 1964 Dec;52:1231-40.

\section{How to cite this article?}

Mohite R.S, Inamdar D.P, Kulkarni V.A, Joshi P, Kulkarni R.D. Demographic trend and clinical features of brucellosis in patients with history of lower back pain - A study in tertiary care hospital . Trop J Path Micro 2018;4(1):46-51.doi: 10.17511/jopm.2018.i1.08. 